\title{
PROTEÇÃO DA GEMA E ÉPOCAS DE FORÇAMENTO DA BROTAÇÃO NA ENXERTIA DA LIMA ÁCIDA 'TAHITI'
}

\author{
Bud protection and timing of bud break treatments on scion, in grafting of Tahiti lime
}

\author{
Dierlei dos Santos ${ }^{1}$, Dalmo Lopes de Siqueira ${ }^{2}$,André Nogueira Borba ${ }^{3}$, Flávia Mara Viera Lelis ${ }^{4}$
}

\begin{abstract}
RESUMO
A produção de mudas de citros em recipientes é uma tecnologia recente, portanto o sistema de produção encontra-se em aperfeiçoamento, havendo necessidade de informações em várias etapas do sistema produtivo, entre elas os métodos de forçamento da brotação pós-enxertia. Objetivou-se, neste trabalho, estudar o efeito da cobertura das gemas com fitas plásticas e da época de forçamento da brotação sobre o pegamento e desenvolvimento de enxertos da lima ácida 'Tahiti'. O porta-enxerto utilizado foi o limoeiro 'Cravo' (Citrus limonia Osbeck), oriundo da germinação de sementes, e a variedade copa a limeira ácida 'Tahiti' (Citrus latifolia Tanaka). Foram testadas épocas de forçamento de brotação da enxertia $(10,15,20,25,30$ e 35 dias após a realização da enxertia) e formas de proteção do enxerto (gema coberta e gema exposta). Após a enxertia as plantas foram mantidas em casa de vegetação com esquema de irrigação por gotejamento. O delineamento experimental foi em blocos casualizados, com cinco repetições e 3 plantas por parcela. Não houve interação entre os fatores estudados, sendo que o índice de pegamento dos enxertos não foi influenciado pelos tratamentos e a cobertura total da borbulha pela fita plástica favoreceu a dormência da gema. O forçamento da brotação do enxerto de lima ácida 'Tahiti', utilizando o método de curvamento do porta-enxerto apresentou os melhores resultados quando esse foi realizado aos 10 dias após a enxertia.
\end{abstract}

Termos para indexação: Produção de mudas, Citrus latifolia, Citrus limonia.

\begin{abstract}
The production of citrus nursery trees in portable containers is a new developing technology and requires investment in research to acquire information on various stages of their production, including the methods to force post grafting bud break. The aim of this work was to investigate the effect of the coverage of buds with plastic tapes as well as the time to force bud break on the establishment and development of 'Tahiti' lime scions. The rootstock used was the 'Rangpur' lime (Citrus limonia Osbeck), obtained from the germination of seeds, while the lime variety 'Tahiti' (Citrus latifolia Tanaka) was used as the scion. The treatments tested were buds covered with plastic tape and uncovered buds at 10,15,20,25, 30, and 35 days after the completion of the budding. After budding, the plants were kept in a greenhouse with dripping irrigation. The experimental design was the randomized blocks, with five replicates and three plants per plot. There was no interaction among the factors studied, while the index of positive grafting was not influenced by the treatments and total coverage of the buds with plastic tape encouraged dormancy of the buds. The bud break of 'Tahiti' lime using the method of bending showed the best results when applied 10 days after grafting.
\end{abstract}

Index terms: Nursery-tree production, Citrus latifolia, Citrus limonia.

(Recebido em 21 de setembro de 2006 e aprovado em 21 de junho de 2008)

\section{INTRODUÇÃO}

A produção de mudas de citros em recipientes é uma tecnologia recente, portanto o sistema de produção encontra-se em aperfeiçoamento, havendo necessidade de informações em várias etapas do sistema produtivo, entre elas os métodos de forçamento da brotação pós-enxertia (PEREIRA \& CARVALHO, 2006).

Não existem informações na literatura científica a respeito da influência do tempo compreendido entre a realização da enxertia e o forçamento da brotação do enxerto sobre o desenvolvimento da muda. Sabe-se, entretanto, que a rápida e uniforme brotação das borbulhas, bem como a redução no período de formação das mudas, pode implicar em menor custo de produção e disponibilidade de mudas em todas as épocas propícias para a comercialização e plantio (COELHO et al., 1983).

O forçamento da brotação das borbulhas na enxertia de citros é feito usando dois métodos básicos, que admitem

${ }^{1}$ Engenheiro Agrônomo, Doutorando em Fitotecnia - Departamento de Fitotecnia/DFT - Setor de Fruticultura - Universidade Federal de Viçosa/UFV Avenida Peter Henry Rolfs, s/n - Campus Universitário - 36570-000 - Viçosa, MG - dierlei@vicosa.ufv.br

${ }^{2}$ Engenheiro Agrônomo, Doutor em Fitotecnia, Professor Adjunto - Departamento de Fitotecnia/DFT - Setor de Fruticultura - Universidade Federal de Viçosa/UFV - Avenida Peter Henry Rolfs, s/n - Campus Universitário - 36570-000 - Viçosa, MG - siqueira@ufv.br

${ }^{3}$ Engenheiro Agrônomo - Departamento de Fitotecnia/DFT - Setor de Fruticultura - Universidade Federal de Viçosa/UFV - Avenida Peter Henry Rolfs, s/n Campus Universitário - 36570-000 - Viçosa, MG - andreagro2000@yahoo.com.br

${ }^{4}$ Engenheira Agrônoma, Mestranda em Fitopatolgia - Departamento de Fitopatologia/DFP - Universidade Federal de Lavras/UFLA - Cx. P. 3037 - $37200-000$ -

Lavras, MG - fvieiralelis@yahoo.com.br 
diversas variações: decapitação (corte do porta-enxerto) ou o seu "curvamento" (DORNELLES et al., 1976).

O forçamento da brotação do tipo curvamento consiste em torcer a haste um pouco acima do local da enxertia e curvar o ramo para o solo, depois de constatado o pegamento do enxerto. Esse processo é útil para ativar o desenvolvimento do enxerto, uma vez que a seiva, devido à curvatura, tende a reduzir a sua velocidade e acumularse na região do enxerto, proporcionando brotação da gema e crescimento vigoroso (MELO, 2003; TODA FRUTA, 2003).

A decapitação do porta-enxerto é uma prática que deve ser revista. Donadio et al. (1974), verificaram que o método de corte parcial e tombamento da copa, resultou em maior vigor da brotação do enxerto para o porta-enxerto limoeiro 'Cravo', quando comparado à decapitação total. Segundo Samson \& Bink (1976), a decapitação total é um método insatisfatório para o forçamento de borbulhas, pois com a eliminação da parte aérea a planta deixa de realizar a fotossíntese, provocando atraso no crescimento do enxerto. Esse é devido às baixas reservas presentes na planta, resultantes da respiração elevada durante todo o ano, característica das plantas cultivadas nos trópicos. Com o porta-enxerto não decapitado e realizando fotossíntese, a parte aérea passa a ser uma fonte importante de reservas para promover o rápido crescimento e desenvolvimento da borbulha. Além disso, o curvamento é uma técnica mais eficiente para estimular a brotação e crescimento das gemas, já que o transporte de auxinas continua ocorrendo em um lado do ramo, enquanto a dominância apical é quebrada somente acima da inserção da borbulha.

Carvalho (1992), comparando métodos de forçamento de enxertia em laranjeira 'Pêra' (Citrus sinensis Osbeck) sobre limoeiro 'Cravo', e Pereira \& Carvalho (2006), realizando o mesmo estudo em laranjeira 'Valência' (Citrus sinensis Osbeck) sobre citrumeleiro 'Swingle' (Citrus paradisi Macfad $x$ Poncirus trifoliata (L.) Raf.), observaram que a decapitação foi mais eficiente na indução da brotação, embora tenha proporcionado menor velocidade no crescimento das mudas. Resultados semelhantes foram obtidos por Williamson et al. (1992) e Williamson \& Maust (1996) que concluem que o curvamento é o método que mais estimula o desenvolvimento, considerando principalmente a altura da haste enxertada.

Pesquisas visando verificar a época adequada para o forçamento da brotação devem levar em conta o período necessário para regeneração e união de tecidos após a enxertia. Segundo Mendel (1936), em citros, a primeira divisão celular ocorre 24 horas após a enxertia, e a primeira ponte de células formada pelo calo produzido na região da enxertia, em direção a borbulha, ocorre após 5 dias. Para a diferenciação do câmbio no porta-enxerto e união com a borbulha são necessários 10 dias e no enxerto, 15 dias, enquanto para a formação dos tecidos xilemáticos do porta-enxerto são necessários 15 dias e na borbulha, 20 dias. Em função disso, é usual entre os viveiristas, remover a fita usada para o amarrilho do enxerto 20 dias após a realização da enxertia, embora o tempo necessário para que haja a plena cicatrização possa variar em função de diversos fatores, como variedades-copa, porta-enxertos, condições climáticas e tratos culturais.

Para a união da borbulha com o porta-enxerto, a fita plástica é a mais usada, por questões técnicas e econômicas (OLIVEIRA et al., 2004). Além da fixação da gema, a fita plástica exerce ao mesmo tempo a função protetora do enxerto, que evita o ressecamento e permite a proliferação de células do porta-enxerto e da borbulha, que completarão a união perfeita entre ambos (MONTENEGRO, 1958; MOREIRA \& RODRIGUES FILHO, 1970). Esses mesmos autores relatam que o efeito da água, tanto de chuva como de irrigação, são prejudiciais ao pegamento dos enxertos, em conseqüência da sua penetração nos cortes.

Aroeira (1960) ressalta a importância da proteção do enxerto com fitas plásticas, quando a enxertia é realizada em condições atmosféricas adversas. Fortes et al. (1970), relatam que, em experimentos realizados em viveiros a "céu aberto", em que se usou fita plástica cobrindo todo o enxerto, o índice de pegamento foi superior ao que se deixou a gema exposta.

As informações descritas anteriormente relatam a importância da fita cobrindo completamente a borbulha para minimizar o efeito adverso do ambiente, porém não há relatos de produção de mudas em ambiente protegido e com irrigação localizada em que se faz uso da fita plástica, porém com a exposição da gema, o que poderia reduzir o tempo necessário para formação da mudas.

Devido ao fato das gemas estarem aptas a brotar logo após a formação do calo e diferenciação do xilema e floema (em torno de 15 dias), teoricamente a brotação e o crescimento dos brotos serão mais rápidos nas borbulhas que receberam o amarrio, deixando a gema exposta e forçadas mais cedo do que as que foram totalmente encobertas e forçadas mais tardiamente.

Objetivou-se, neste trabalho, foi estudar a interação entre a proteção ou não da gema com fita plástica no momento do amario, com a época de forçamento da brotação, sobre o pegamento e desenvolvimento dos enxertos de lima ácida 'Tahiti' (Citrus latifolia Tanaka) sobre limoeiro ‘Cravo' (Citrus limonia Osbeck). 


\section{MATERIALE MÉTODOS}

O experimento foi conduzido em viveiro com cobertura plástica e proteção lateral com tela ante-afídios, no setor de Fruticultura, localizado no Campus da UFV, no período de junho de 2005 a maio de 2006.

$\mathrm{Na}$ formação dos porta-enxertos utilizaram-se sementes de limoeiro 'Cravo' (Citrus limonia Osbeck), retiradas de frutos maduros em junho de 2005. Essas foram tratadas com cal hidratada para remoção da mucilagem e após secas à sombra durante 3 dias, foram colocadas em câmara de germinação à temperatura de $30^{\circ} \mathrm{C}$ e umidade relativa de $75 \%$ por 15 dias, para a germinação. Em julho, as sementes germinadas (com emissão da radícula) foram colocadas em tubetes de $125 \mathrm{~mm}$ de comprimento com capacidade de $55 \mathrm{~cm}^{3}$, preenchidos com substrato comercial Plantmax. Setenta e cinco dias após, quando atingiram 10 $\mathrm{cm}$ de altura, as mudas foram transplantados para sacos de polietileno com dimensões de $15 \mathrm{~cm}$ de diâmetro por 30 cm de altura, preenchidos com a mistura de $1 / 3$ de esterco de curral curtido, 1/3 de terra de barranco e 1/3 de areia, acrescido de $5 \mathrm{~kg} / \mathrm{m}^{3}$ de superfosfato simples e $0,2 \mathrm{~kg} / \mathrm{m}^{3}$ de cloreto de potássio.

$\mathrm{O}$ experimento foi delineado em blocos casualizados, com 5 repetições e 3 plantas por parcela em esquema fatorial $6 \times 2$, totalizando 180 plantas. $\mathrm{O}$ forçamento da brotação do enxerto consistiu no curvamento do portaenxerto para o lado oposto à inserção da borbulha, prendendo-se à parte superior da haste na sua própria base junto ao vaso. $\mathrm{O}$ forçamento das brotações foi realizado aos 10, 15, 20, 25, 30 e 35 dias após a realização da enxertia. Também foram testadas duas formas de proteção do enxerto: com a gema coberta com fita plástica e com a gema exposta.

As enxertias do tipo " $\mathrm{T}$ " invertido foram realizadas em fevereiro de 2006 com borbulhas de lima ácida 'Tahiti' (Citrus latifolia Tanaka), na altura aproximada de $15 \mathrm{~cm}$ a partir do colo da planta, quando os porta-enxertos apresentavam diâmetro em torno de $8,0 \mathrm{~mm}$. Para todos os tratamentos, a retirada da fita plástica transparente foi realizada dois dias após o forçamento correspondendo a $12,17,22,27,32$ e 37 dias após a enxertia.

Durante a realização do experimento, as plantas receberam os devidos tratos culturais, como capinas, desbrotas, controle de pragas e adubações, conforme recomendação de Carvalho (2001). As irrigações foram feitas de forma localizada por gotejamento, para não molhar o local da enxertia.

As características avaliadas foram: pegamento do enxerto expresso em porcentagem; dormência da borbulha também expresso em porcentagem sendo caracterizada pela ausência de brotação das gemas que mantinham a coloração verde, indicando que estavam vivas; diâmetro do enxerto $5 \mathrm{~cm}$ acima do ponto de enxertia; número de surtos de crescimento na haste do enxerto; comprimento do enxerto e comprimento médio de entrenós, que foi mensurado tomando-se o comprimento total do enxerto dividindo-se pelo número de nós contidos na haste.

A primeira coleta de dados foi feita 50 dias após a realização da enxertia e outras duas a cada 30 dias. Porém, decidiu-se avaliar apenas a altura do enxerto nas três coletas, por ser uma característica de maior utilidade para os viveiristas. Os outros dados foram avaliados apenas quando as mudas encontravam-se com 120 dias após a enxertia, apresentando tamanho adequado de serem levadas para o campo, produzidas em haste única. Nesse momento também foi realizada a decapitação total do portaenxerto.

Os dados foram submetidos à análise de variância, sendo as médias dos tratamentos relativos à porcentagem de pegamento e dormência das gemas, após serem transformados segundo arco seno de $(\mathrm{x} / 100)^{0,5}$, foram comparadas pelo teste de Tukey, $(\mathrm{a}=0,05)$. Os demais dados não sofreram transformações, e foram submetidos à análise de regressão, sendo que os modelos foram escolhidos com base na significância dos coeficientes, utilizando-se o teste ' $t$ ', a $5 \%$ de probabilidade. Não foi necessário fazer desdobramento do fatorial.

\section{RESULTADOS E DISCUSSÃO}

Não ocorreram interações significativas entre épocas de forçamento e tipo de proteção dos enxertos em nenhuma das avaliações realizadas.

Houve pegamento de 93,4 \% dos enxertos realizados (Tabela 1). As mortes ocorreram de forma aleatória no experimento, sem influência dos tratamentos. Esse valor é semelhante àqueles freqüentemente obtidos em viveiros comerciais e relatados em outros experimentos com Citrus, (90-95\%) (OLIVEIRA et al., 2001).

Um dos fatores que poderia causar mortalidade seria a umidade na região da enxertia dos tratamentos, com a gema desprotegida (MONTENEGRO, 1958; MOREIRA \& RODRIGUES FILHO, 1970), porém não houve esse problema porque a irrigação foi realizada de forma localizada.

Quanto à dormência das gemas, também houve efeito significativo para as épocas de forçamento, indicando que os enxertos forçados mais precocemente (de 10 a 20 dias), apresentaram dormência variando aproximadamente de 3 a 10\%. Forçamentos realizados mais tardiamente (35 
dias), provocaram dormência em $50 \%$ das plantas enxertadas (Tabela 1). Esses resultados são diferentes dos encontrados por Williamson \& Maust (1996), que obtiveram $59 \%$ de dormência de gemas utilizando vergamento em enxertos forçados 20 dias após a realização da enxertia em laranja 'Hamlin' sobre citrumelo 'Swingle'.

Também houve efeito do tipo de proteção sob a dormência da gema (Figura 1). Enxertos com gemas totalmente cobertas apresentaram $31 \%$ de dormência, independente da época de forçamento, ao passo que nas que permaneceram expostas, o índice de dormência foi de $15,5 \%$, indicando superioridade de $100 \%$ no porcentual de gemas dormentes quando são mantidas cobertas durante o processo de enxertia sob essas condições de realização do trabalho. O maior porcentual de gemas dormentes em condições totalmente cobertas pode ser devido ao fato de estarem com a máxima capacidade de brotarem por volta dos 10 aos 20 dias, por causa das condições anatômicas do enxerto e porta-enxerto (MENDEL, 1936), porém passada essa fase, a gema introduzida passa a se comportar como sendo uma das constituintes normais da planta, e como a dominância apical não é quebrada e a fita plástica não é removida, logo diminui a aptidão para brotar, sendo algumas mais tarde envolvidas pela casca do porta-enxerto.

As mudas emitiram um único surto de brotação independentemente do tipo de tratamento submetido (Tabela 1). A emissão de mais de um surto de brotação atrasa a formação da muda cítrica, sendo que, às vezes, o enxerto pode necessitar de até 3 surtos de crescimento, entretanto, o ideal é que a muda esteja pronta com um único surto, uma vez que cada interrupção no crescimento pode atrasar sua formação (BERNARDI et al., 2000). Araújo \& Souza (1994) observaram que mudas formadas com 2 surtos de crescimento atingiram a altura de desponte $(60 \mathrm{~cm}) 2,5$ meses mais tarde que as mudas formadas em um único surto.

Tabela 1 - Avaliação do pegamento, dormência e número de surtos de crescimento em enxertos de lima ácida 'Tahiti' sobre limoeiro 'Cravo', submetidos a diferentes épocas de forçamento.

\begin{tabular}{cccc}
\hline Forçamento (dias após enxertia) & Pegamento $(\%)$ & Dormência $(\%)$ & Surtos $^{\left(\mathrm{n}^{\circ}\right)}$ \\
\hline 10 & $93,4 \mathrm{a}$ & $3,3 \mathrm{a}$ & $1 \mathrm{a}$ \\
15 & $100,0 \mathrm{a}$ & $6,6 \mathrm{a}$ & $1 \mathrm{a}$ \\
20 & $96,7 \mathrm{a}$ & $10,0 \mathrm{a}$ & $1 \mathrm{a}$ \\
25 & $86,8 \mathrm{a}$ & $33,3 \mathrm{ab}$ & $1 \mathrm{a}$ \\
30 & $93,4 \mathrm{a}$ & $36,7 \mathrm{ab}$ & $1 \mathrm{a}$ \\
\hline $\mathrm{CV}(\%)$ & $90,1 \mathrm{a}$ & $50,0 \mathrm{~b}$ & 0,00 \\
\hline
\end{tabular}

Médias seguidas pela mesma letra minúscula na coluna não diferem entre si, pelo teste de Tukey, ao nível de $5 \%$ de probabilidade.

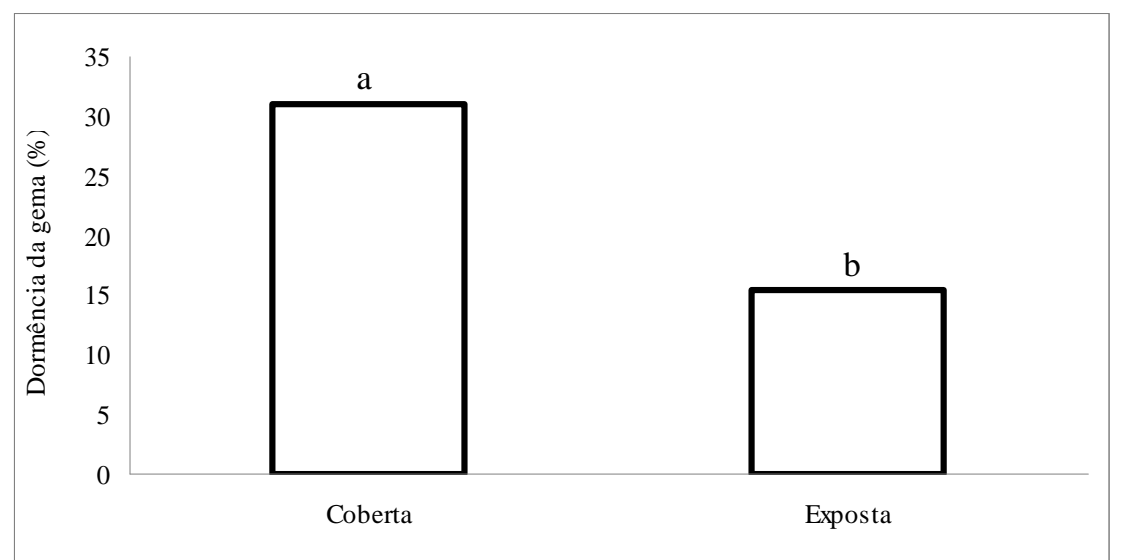

Figura 1 - Diferença no porcentual de enxertos dormentes nos dois métodos de proteção da borbulha em lima ácida 'Tahiti' sobre limoeiro 'Cravo'. 
Para a altura, diâmetro médio do enxerto e comprimento médio dos entrenós houve efeito significativo apenas para as épocas de forçamento de brotação do enxerto, não havendo influência do tipo de proteção da gema.

Enxertos forçados mais precocemente, tiveram brotos com maior tamanho em todas as avaliações (50, 80 e 120 dias), sendo que essa característica apresentou comportamento linear decrescente conforme se distanciava o forçamento da época de realização da enxertia (Figura 2).

$\mathrm{Na}$ avaliação aos 50, 80, e 120 dias, o broto dos enxertos forçados no $10^{\circ}$ dia atingiram altura de $38,33,50,00$ e $66,55 \mathrm{~cm}$ respectivamente, sendo que os forçados aos 35 dias atingiram tamanho de 0,00, 6,20 e 11,10 cm, correspondente apenas a 16,6\% dos forçados aos 10 dias, indicando uma grande diferença no tamanho final do broto do enxerto apenas por um atraso na época do forçamento da enxertia (Figura 2).

Outra observação relevante está no fato de que os enxertos seguiram praticamente a mesma dinâmica de crescimento em altura, ou seja, a diferença entre os tratamentos foi proporcional dos 50 aos 120 dias após a enxertia (Figura 2). Esses resultados demonstram que o atraso na brotação ou desenvolvimento inicial do enxerto resulta em maior tempo para produção da muda, significando prejuízo aos viveiristas a não observância desses fatores. Não foram encontrados resultados na literatura que pudessem ser confrontados com os obtidos nesse trabalho quando á influência do período de forçamento no desenvolvimento da muda de 'Tahiti' sobre
'Cravo'. O que provavelmente ocorre é que o enxerto encontra-se em sua plenitude para brotar entre o $10^{\circ}$ e $20^{\circ}$ dia após enxertia e, se o forçamento não for realizado nessa época, o porta-enxerto parece competir com a borbulha por fotoassimilados, além de exercer a dominância apical, inibindo a brotação e retardando o crescimento.

$\mathrm{O}$ diâmetro do enxerto medido $5 \mathrm{~cm}$ acima do local da enxertia, também foi influenciado pelas épocas de forçamento, apresentando comportamento linear decrescente (Figura 3). Quando o forçamento da brotação foi efetuado no $10^{\circ}$ dia após a realização da enxertia, o diâmetro médio foi próximo de $7,9 \mathrm{~mm}$ ao passo que os forçados no $35^{\circ}$ dia apresentaram diâmetro próximo de 3,38 $\mathrm{mm}$, sendo esse valor apenas $42 \%$ do primeiro. Essa diferença no diâmetro é facilmente explicada, pois a redução acompanhou a mesma tendência da altura dos enxertos, sendo que quanto mais tarde se realiza o forçamento, menor a altura do enxerto e, conseqüentemente, menor seu diâmetro.

Quanto aos entrenós, esses se ajustaram a uma equação quádratica, sendo que o máximo comprimento foi atingido quando os enxertos foram forçados no $15^{\circ}$ dia (20,75 mm) após a realização da enxertia (Figura 4). Quando foram forçados no $10^{\circ}$ dia, houve redução apenas de 3,25 $\%$ no comprimento, ao passo que os forçados aos 30 e 35 dias, sofreram redução de $27,9 \%$ e $50,24 \%$, respectivamente. Esse resultado indica que o crescimento do enxerto está relacionado, além do maior alongamento do entrenó, também ao aumento de seu número.

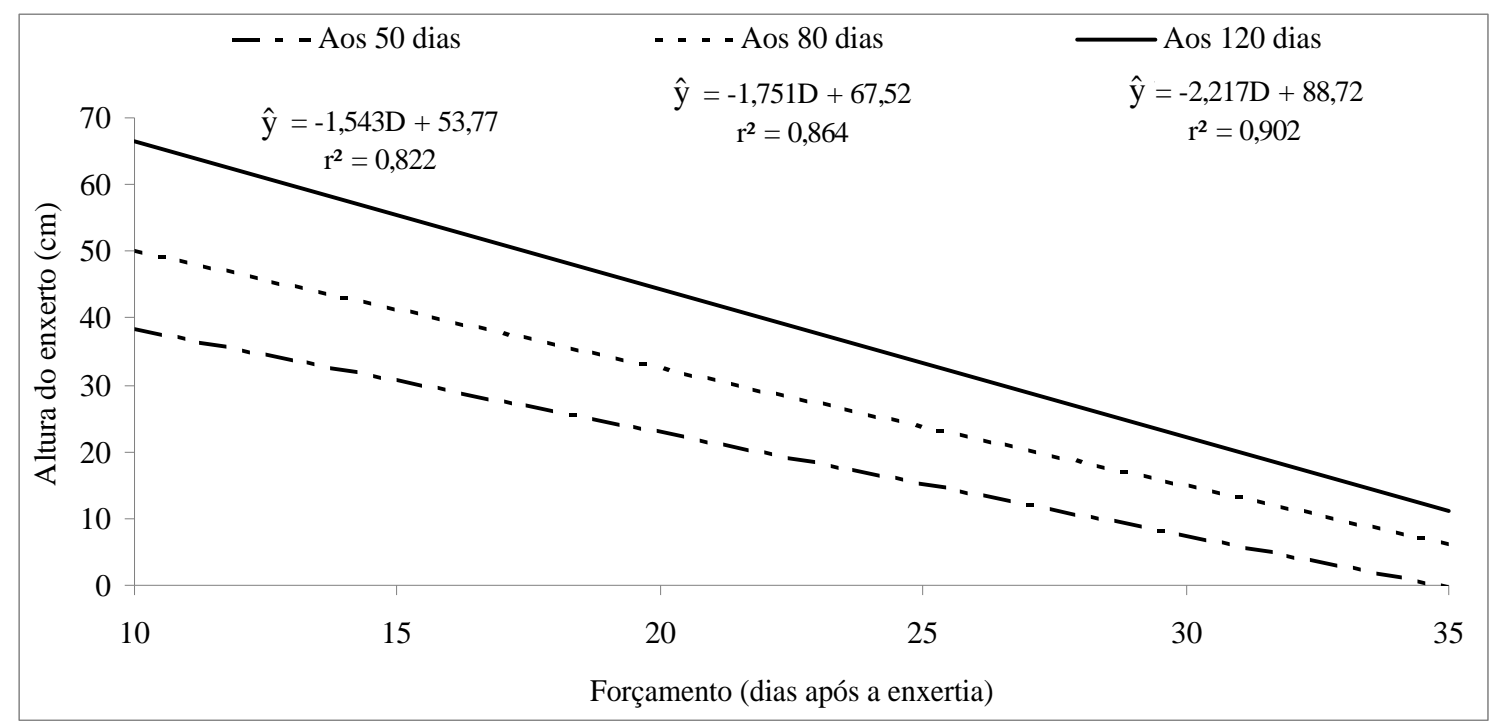

Figura 2 - Altura alcançada pelos brotos dos enxertos nas três avaliações, aos 50, 80 e 120 dias após a realização da enxertia em diferentes épocas de forçamento em lima ácida 'Tahiti' sobre limoeiro 'Cravo'. 


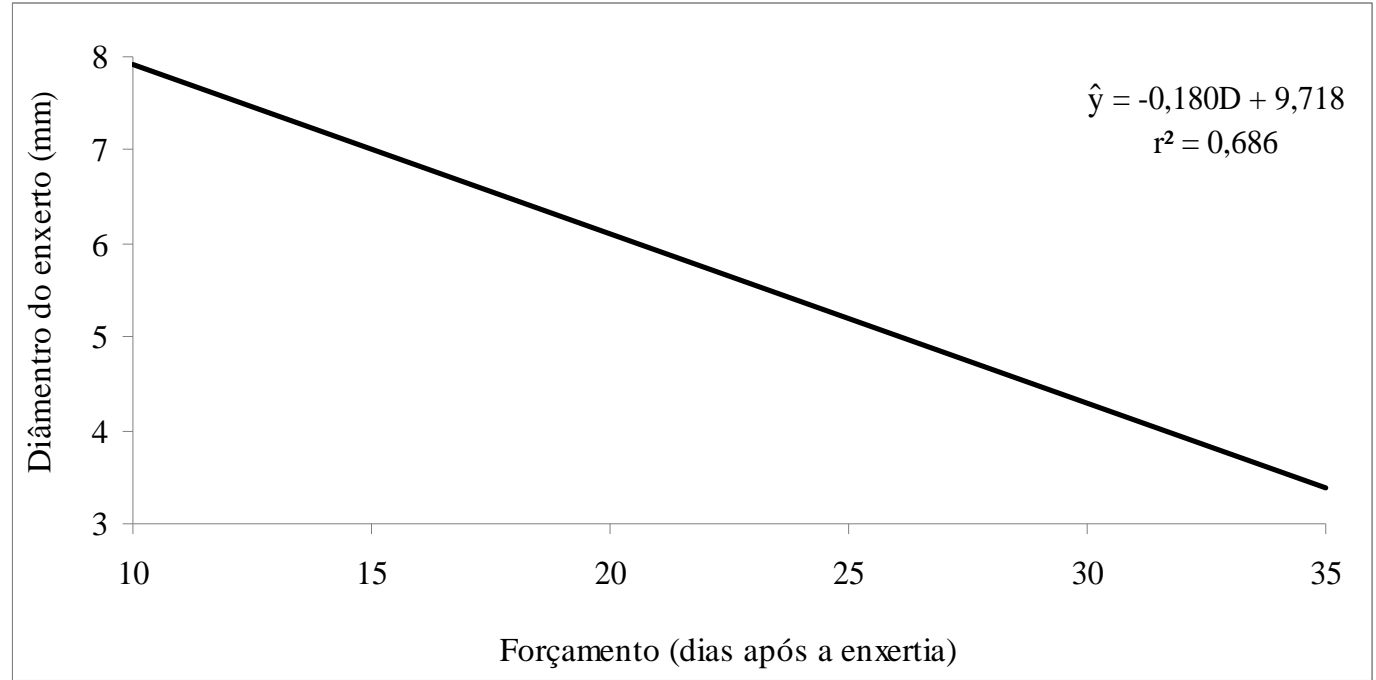

Figura 3 - Diâmetro dos enxertos aos 120 dias após a realização da enxertia em diferentes épocas de forçamento em lima ácida 'Tahiti' sobre limoeiro 'Cravo'.

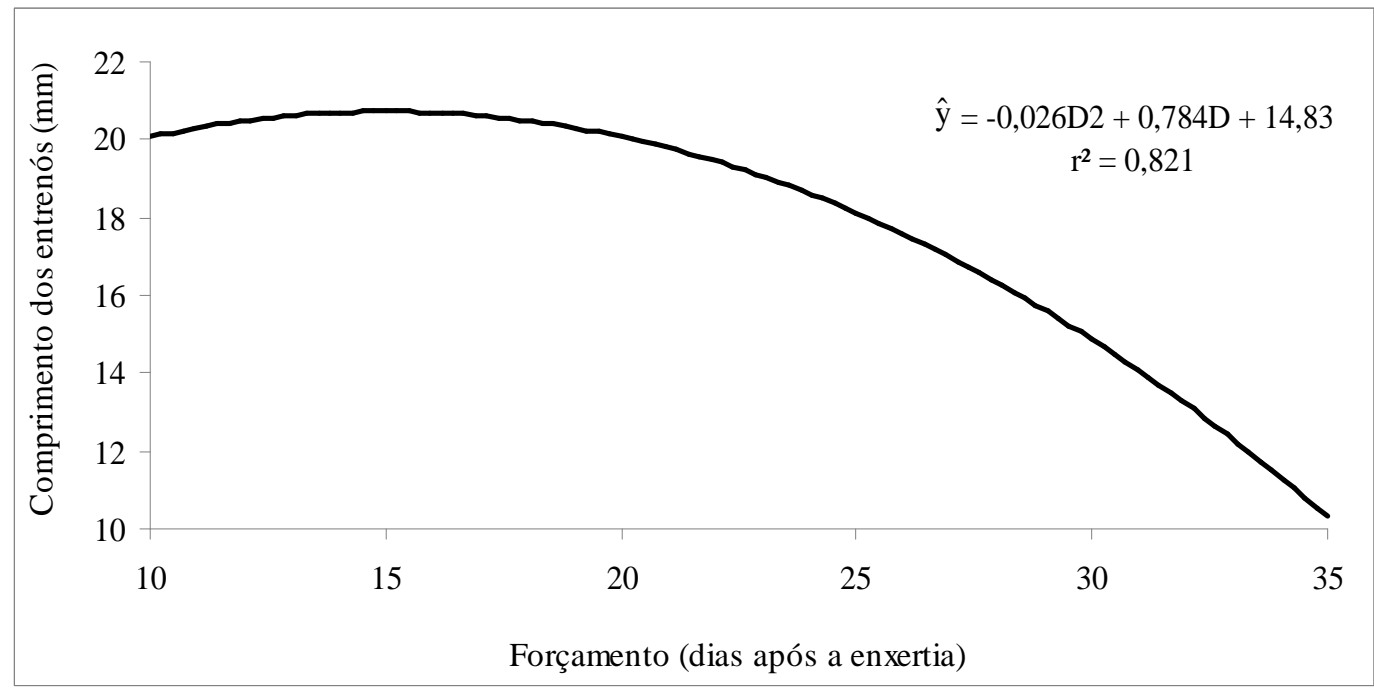

Figura 4 - Comprimento dos entrenós aos 120 dias após a realização da enxertia em diferentes épocas de forçamento em lima ácida 'Tahiti' sobre limoeiro ‘Cravo'.

\section{CONCLUSÕES}

O índice de pegamento dos enxertos não foi influenciado pelos tratamentos e a cobertura total da borbulha pela fita plástica favoreceu a dormência da gema.

O forçamento da brotação do enxerto de lima ácida 'Tahiti', utilizando-se o método de curvamento do portaenxerto, apresentou os melhores resultados quando foi realizado aos 10 dias após a enxertia.

\section{REFERÊNCIAS BIBLIOGRÁFICAS}

ARAÚJO, S. C.; SOUZA, M. Influência da adubação e vigor dos ramos porta borbulhas na qualidade dos enxertos de citros. Ciência e Prática, Lavras, v. 18, p. 151-157, 1994.

AROEIRA, J. S. Fruticultura geral. Viçosa: Universidade Rural do Estado de Minas Gerais, 1960. 125 p. 
BERNARDI, A. C. C.; CARMELLO, Q. A. C.; CARVALHO, S. A. Desenvolvimento de mudas de citros cultivadas em vaso em resposta à adubação NPK.

Scientia Agricola, Piracicaba, v. 57, n. 4, p. 733-738, out./ dez. 2000.

CARVALHO, E. F. Efeito do método de indução de brotação sobre o "pegamento" e crescimento da haste do enxerto de laranja 'Pera'. Pesquisa Agropecuária Brasileira, Brasília, v. 27, n. 3, p. 473-478, 1992.

CARVALHO, S. A. Propagação dos citros. Informe Agropecuário, Belo Horizonte, v. 22, n. 209, p. 21-25, 2001.

COELHO, Y. S.; OLIVEIRA, A. A. R.; CALDAS, R. C. Efeitos do ácido giberélico $\left(\mathrm{GA}_{3}\right)$ no crescimento de porta-enxertos para citros. Pesquisa Agropecuária Brasileira, Brasília, v. 18, p. 1229-1232, 1983.

DONADIO, L. C. et al. Estudos de tipos de forçamento do enxerto de laranja Natal nucelar (Citrus sinensis (L.) Osb). Bragantia, Campinas, v. 33, 1974.

DORNELLES, C. M. M. et al. Experimentos comparativos de épocas e alturas de corte de porta-enxertos de citros em enxertia de primavera. In: CONGRESSO BRASILEIRO DE FRUTICULTURA, 3., 1975, Rio de Janeiro, RJ.

Anais... Campinas: Sociedade Brasileira de Fruticultura, 1976. p. 349-358.

FORTES, J. M.; PINHEIRO, R. V. R.; TEIXEIRA, S. L. Influência do tipo de amario no pegamento de enxertos de citros ( $C$. sinensis Osbeck) na época chuvosa.

Revista Ceres, Viçosa, v. 13, n. 94, p. 332-337, 1970.

MELO, B. Reprodução de fruteiras. Uberlândia: UFU/ ICIAG, 2003. Disponível em: <http:// Www.fruticultura.iciag.ufu.bìt/ reprodução.html >. Acesso em: 4 jul. 2006.

MENDEL, K. The anatomy and histology of the budunion in Citrus in Palestine. Journal of Botany Horticultural Science, v. 1, n. 2, p. 13-46, 1936.
MONTENEGRO, H. W. S. Curso avançado de citricultura. Piracicaba: ESALQ, 1958. 241 p.

MOREIRA, S.; RODRIGUES FILHO, A. J. Cultura dos citrus. São Paulo: Melhoramentos, 1970. 120 p.

OLIVEIRA, R. P.; SCIVITTARO, W. B.; MACHADO, M. A. Variabilidade do vigor e do pegamento de enxertia de híbridos de tangerina 'Cravo' com laranja 'Pêra'. Revista Brasileira de Fruticultura, Jaboticabal, v. 23, n. 1, p. 134-137, 2001.

OLIVEIRA, R. P.; SCIVITTARO, W. B.; VARGAS, J. R. Fita plástica e fita degradável na enxertia de citros.

Revista Brasileira de Fruticultura, Jaboticabal, v. 26, n. 2, p. 564-566, 2004.

PEREIRA, B. F. F.; CARVALHO, S. A. Métodos de forçamento de borbulhas e aplicação de cianamida hidrogenada para produção de mudas de laranja 'valência' sobre citrumelo 'swingle' em viveiro telado. Revista Brasileira de Fruticultura, Jaboticabal, v. 28, n. 1, p. 151-153, 2006.

SAMSON, J. A.; BINK, J. P. M. Citrus budding in the tropics: towards explanation of the favorable results of lopping. In: CONFERENCE OF THE INTERNATIONAL ORGANIZATION OF CITRUS VIROLOGISTS, 7., 1975, Atenas. Proceedings... Riverside: IOCV, 1976. p. 213-231.

TODA FRUTA. Mudas de frutíferas. 2003. Disponível em: 〈http://www.todafruta.com.br/todafrutah imostra_conteudo 1. Acesso em: 4 jul. 2006.

WILLIAMSON, J. G.; CASTLE, W. S.; KOCH, K. E. Growth and ${ }^{14} \mathrm{C}$-photosynthase allocation in citrus nursery trees subjected to one of three bud-forcing methods. Journal of the American Society for Horticultural Science, v. 117, n. 1, p. 37-40, 1992.

WILLIAMSON, J. G.; MAUST, B. E. Forcing treatment and rootstock affect budbreak and growth of containerized Citrus nursery trees. Hort Technology, v. 6, n. 2, p. 134-137, 1996. 